This item was submitted to Loughborough's Research Repository by the author.

Items in Figshare are protected by copyright, with all rights reserved, unless otherwise indicated.

\title{
Mechanical response of indium micro-joints to low temperature cycling
}

PLEASE CITE THE PUBLISHED VERSION

PUBLISHER

(C) IEEE

VERSION

VoR (Version of Record)

LICENCE

CC BY-NC-ND 4.0

\section{REPOSITORY RECORD}

Cheng, X., Changqing Liu, and Vadim V. Silberschmidt. 2019. "Mechanical Response of Indium Micro-joints to Low Temperature Cycling”. figshare. https://hdl.handle.net/2134/5332. 
This item was submitted to Loughborough's Institutional Repository (https://dspace.lboro.ac.uk/) by the author and is made available under the following Creative Commons Licence conditions.

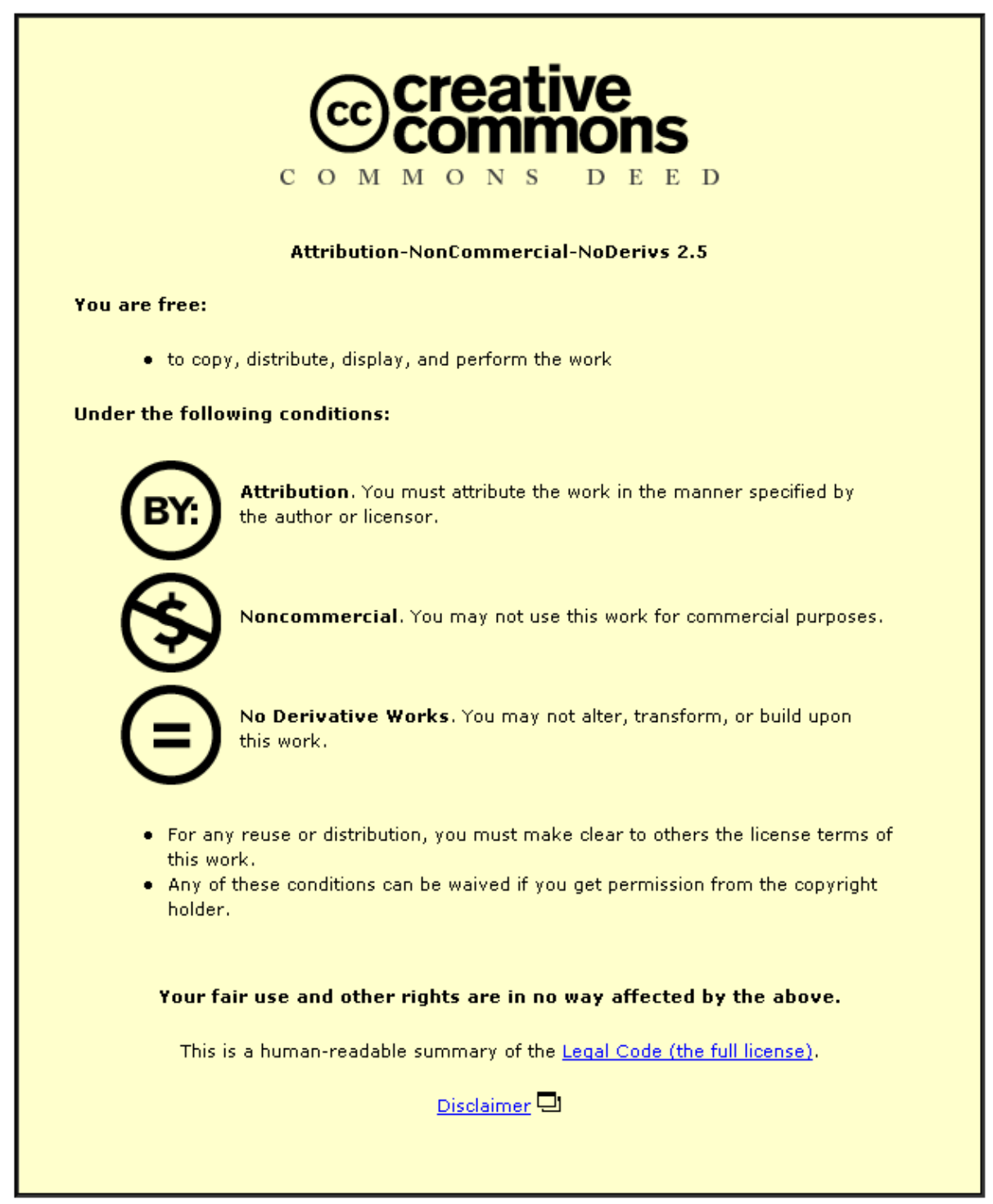

For the full text of this licence, please go to: http://creativecommons.org/licenses/by-nc-nd/2.5/ 


\title{
Mechanical Response of Indium Micro-joints to Low Temperature Cycling
}

\author{
X. Cheng, C. Liu, V.V. Silberschmidt \\ Wolfson School of Mechanical and Manufacturing Engineering, \\ Loughborough University, LE11 3TU, United Kingdom \\ Email: X.cheng@lboro.ac.uk
}

\begin{abstract}
In this study, mechanical properties of indium micro-joints exposed to low temperature cycling were investigated. The metallization structure of $\mathrm{Ni} / \mathrm{Cu}$ was specially used as a substrate to form indium joints for mechanical tests. This paper focuses mainly on the tensile test of indium joints at thermal cycling from $300 \mathrm{~K}$ to $77 \mathrm{~K}$. The Young's modulus, the ultimate strength and yield strength of the material were obtained. The failure mode after different loading histories was analyzed. The results indicate the decline of the Young's modulus with the increase in the number of thermal cycles; however, the ultimate/yield strength of indium joints did not show an obvious trend with the number of thermal cycling. It was confirmed that indium joints still maintain a high ductility even after 20 thermal cycles. Finally, the associated modeling provides an insight predicting that an interface between indium and copper could be the potential site for failure in thermal cycling.
\end{abstract}

Keywords; Indium; the liquid nitrogen temperature; reliability

\section{Introduction}

Indium is of considerable interest for applications in electronics packaging due to its excellent plasticity and selfalignment capability. Indium has been widely used in flip chip interconnections, which can offer high $\mathrm{I} / \mathrm{Os}$, fine pitch and small bumps $(<20 \mu \mathrm{m})$. In particular, a mismatch of coefficients of thermal expansion between a substrate and the connected chip, which is one of the most critical reliability issues in flip chip assembly, can be accommodated due to indium's excellent ductility [1]. Furthermore, soldering with indium is considered as a low-temperature process, which has been lately employed in a number of applications, such as 3D wafer stacking. A typical application is using the indium bump-bonding for the electronics integration of hybrid pixel detectors. Such detectors comprise a crystalline semiconductor that is often bump-bonded to a pixellated application specific integrated circuit (ASIC) readout chip. It is within this context that the reliability issues associated with service conditions of the hybrid pixel detector were concerned in terms of functioning in a harsh environment, namely, at significant temperature variations - from the room temperature to the liquid nitrogen temperature [2]. The objective of this paper is to investigate the microstructure and mechanical properties of indium micro-joints during the low temperature cycling between $300 \mathrm{~K}$ and $77 \mathrm{~K}$.

Some investigations on the low-temperature properties of bulk indium metal have been relatively well documented. The studies of the tensile behaviour of indium by Reed et al. [3] identified the strain-hardening and deformation-twinning characteristics at $4.10 \mathrm{~K}$ and $76 \mathrm{~K}$. Mechanical twinning in indium was reported by Remaut et al. [4] and Becker et al. [5], reviewed by Hall [6], and studied in In-Th alloys by Wuttig and Lin [7]. Elastic properties of indium were determined by Kim and Ledbetter [8], with the Young's modulus magnitudes of $12.61 \mathrm{GPa}$ at $300 \mathrm{~K}, 18.36 \mathrm{GPa}$ at 80 $\mathrm{K}$ and $19.56 \mathrm{GPa}$ at $5 \mathrm{~K}$. Some compressive data on stressstrain characteristics of indium at low temperature were also obtained by Swenson [9] in the study of its compressibility. However, all of these investigations were based on tests of bulk specimens of indium or its alloys. The low-temperature properties of indium joints at a microscopic scale are expected to be different since the dimensions of indium joints are reduced to a length scale, at which mechanical and fatigue properties of each grain can have a significant influence on overall reliability due to the anisotropic characteristics. Therefore, it is important to understand the mechanical behavior of such indium micro-joints at low temperature under conditions close to those of the joints used in the hybrid pixel detector.

\section{Experimental details}

\subsection{Material}

The tensile specimens of indium micro-joints were prepared in a metalized copper substrates with a multilayered structure of $\mathrm{Cu} / \mathrm{Ni} / \mathrm{In} / \mathrm{Ni} / \mathrm{Cu}$. The indium was received from the Indium Corporation as ingots, which were rolled into the thin sheets as-required dimension with certain thickness. As copper is one of the most common substrate used in the electronics packaging, high purity copper $(\mathrm{Cu})$ with $1 \mathrm{~mm}$ thickness was used as the substrate for the fabrication of tensile testing specimens with the inserts of thin layer of indium. Nickel (Ni) was electroplated on the copper substrate prior to the indium soldering in order to minimize the effects of the $\mathrm{Cu}$-In intermetallic compounds on the mechanical testing of indium joints. Although $\mathrm{Au} / \mathrm{Ni} / \mathrm{Cu}$ is commonly used as the main substrate and metallization for the electronics integration of hybrid pixel detectors, it was recognized that the high diffusion of $\mathrm{Au}$ into the indium joints may become a concern for reliability. The electroplating apparatus use for nickel metallization is shown in Figure 1; it consists of the computer control system, power supply and electroplating cell. The electrolytic solution is made of nickel sulfamate and the boric acid. 


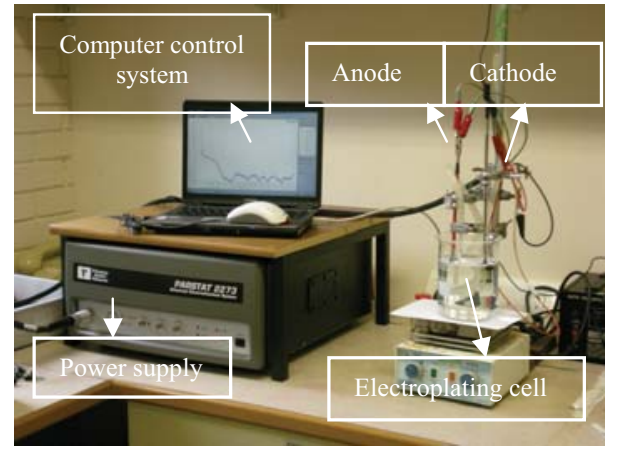

Figure 1: Electroplating apparatus

\subsection{Procedures}

The tensile specimens were prepared with the specific micrometer-driven device in order to control the thickness of the joint between two Ni layers as shown in Figure 2. This is to ensure the reliable mechanical data of indium joint. The indium joints were formed between two pieces of electroplated $\mathrm{Ni} / \mathrm{Cu}$, the copper substrate are $80 \mathrm{~mm} \times 30 \mathrm{~mm}$ with $1 \mathrm{~mm}$ thickness. For the reflow process, a Planer TTrack $\odot$ reflow oven was used in the ambient condition. To

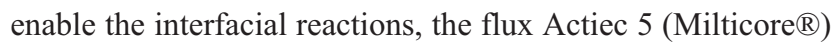
was applied to the $\mathrm{Ni} / \mathrm{Cu}$ substrates prior to the insertion of a thin sheet of indium. After reflow, all the large planar joints were cut into small specimens along the cross-section of the welding line to produce a number of testing samples with a width of approximately $10 \mathrm{~mm}$. The cutting process was performed with a low-speed saw, inducing little mechanical damage to the joints during the cutting process. In this study, indium joints with the thickness of $300 \mu \mathrm{m}$ were made.

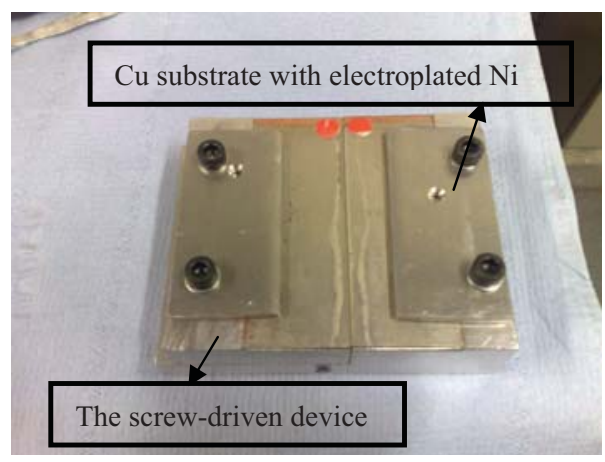

Figure 2 Screw-driven device for joint fabrication

Figure 3 provides the dimensions of the tensile test specimens used in this study. A strong flux was used to ensure the good interconnects between indium and nickel during soldering process.

After the cutting process, six specimens per group were utilized with thermal loading shown in Figure 4. The tensile tests were performed before the thermal cycling, and after 10 and 20 cycles with MicroTester (Instron ${ }^{\circledR} 5800$ ). Specimen's strain was monitored and recorded using a strain gauge extensomenters. The cross-head displacement rate for the tensile tests was $0.08 \mathrm{~mm} / \mathrm{min}$ (the strain rate is around
$2.5 \times 10-5 \mathrm{~s}-1)$. The tensile properties of indium joint at micro scale with thermal cycling were investigated in details.

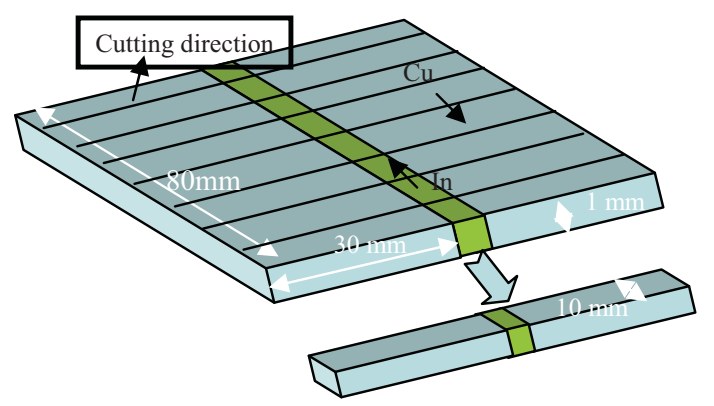

Figure 3: Tensile testing specimen of micro-indium joints interconnected to Ni metalized layer

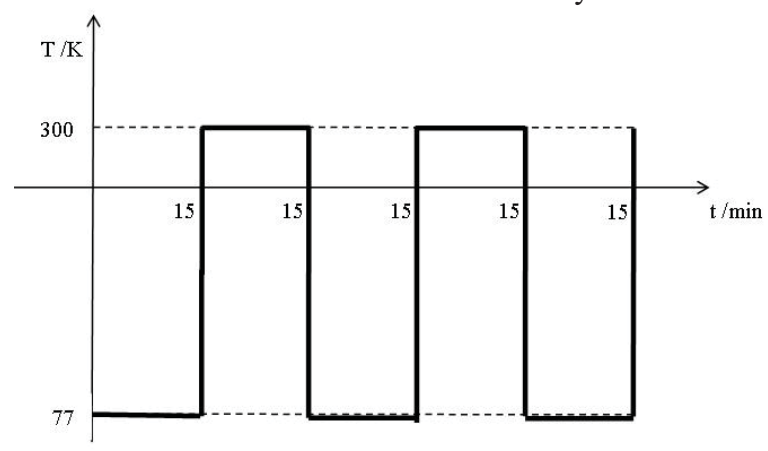

Figure 4: Temperature profile for thermal cycling tests

The modeling and simulation on the mechanical performance of indium joint at low temperature cycling were performed as well. The stress distribution and evolution of indium joint $(300 \mu \mathrm{m})$ during 1 thermal cycle was studied.

\section{Results}

\subsection{Effect of thermal cycling on tensile properties}

The tensile test data after thermal cycling has been collected, which include Young's modulus, ultimate strength, engineering stress-strain from the indium micro-joint after 20 cycles, and the results are given in Figure 5, 6 and 7.

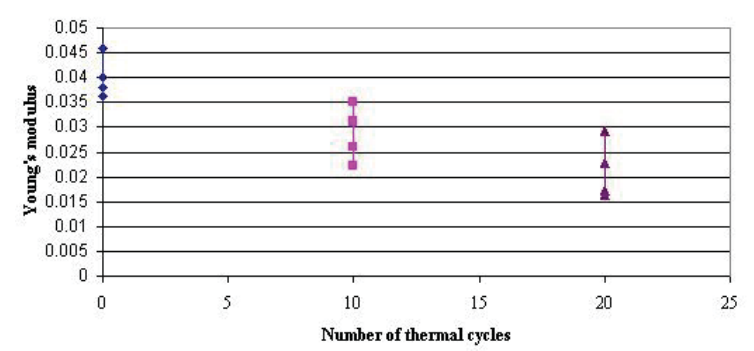

Figure 5 Evolution of Young's modulus of $\mathrm{In} / \mathrm{Ni} / \mathrm{Cu}$ with thermal cycles

As seen in Figure 5, the Young's modulus of indium joints decreases with the increase in the number of thermal cycles. However, the data of the ultimate strength (Figure 6) and the yield strength of indium joint were relatively scattered, with the extent of scatter increasing with the 
loading history. This may be attributed to the slight variations of the individual specimens, therefore the deviation did not show a particular trends. Further tests with more specimens are needed to establish such trends; this study is currently ongoing. In terms of the engineering stress-strain relation due to the thermal cycling, indium joints with $\mathrm{Ni} / \mathrm{Cu}$ still maintain sufficient ductility even after 20 thermal cycles (see in Figure 7). Tests with more thermal cycles are being conducted to analyze this behavior.

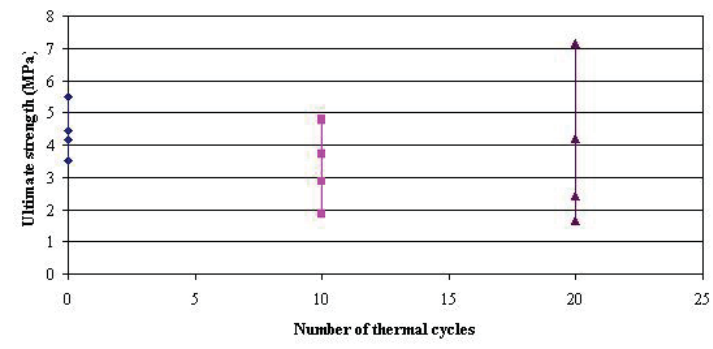

Figure 6 Evolution of Ultimate strength of $\mathrm{In} / \mathrm{Ni} / \mathrm{Cu}$ with thermal cycles

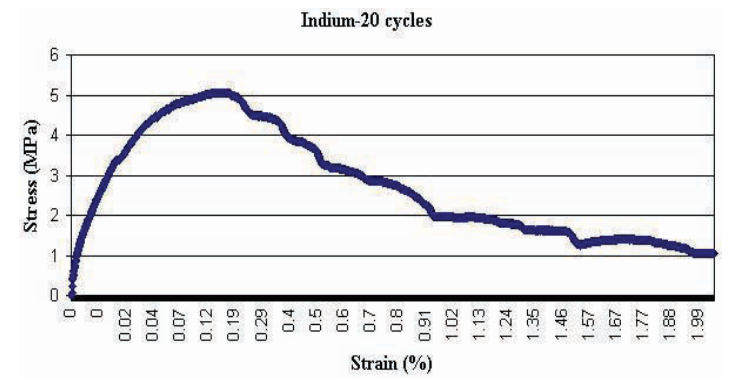

Figure 7 Stress-strain curve of indium joint after 20 cycles

\subsection{Possible failure modes of micro-joint of indium due to thermal cycling Text about the next steps in your analysis}

Results for the engineering stress-strain relation of indium joint with thermal cycling suggest that the failure modes of micro-joints of indium even after 20 cycles are prone to plastic failure with obvious hardening and inelastic deformation, such as necking. As shown in Figure 8, the fracture site demonstrates significant plastic deformation, and the brittle fracture appeared after 3 cycles, which mainly occurred at the interface between indium and the $\mathrm{Ni} / \mathrm{Cu}$ substrate. It should be linked with the mismatch of the coefficients of thermal expansion (CTE) of indium and copper, which was investigated in the modeling and simulation of stress concentration in the indium micro-joint due to thermal cycling as described below.

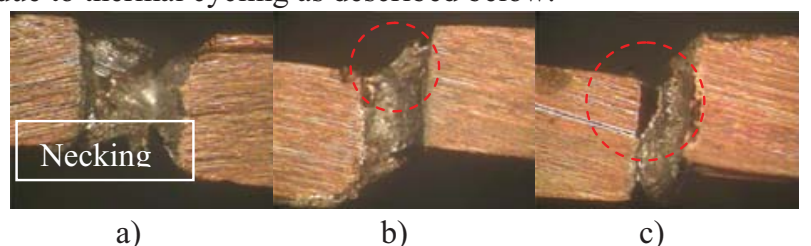

a)

b)

Figure 8 Microscopic images of fracture in indium joints with different thermal histories: a) after 1 cycle; b) after 3 cycles and c) after 20 cycles

\subsection{Numerical analysis of stress concentration in indium} micro-joint due to thermal cycling

Based on our experimental work, the effect of thermal cycling from the room temperature to the liquid nitrogen temperature was simulated in order to assist the fundamental understanding of the mechanical behavior of the indium micro-joints. The finite-element software ABAQUS, which is usually used to model the thermo-mechanical behavior of materials, was employed to simulate the stress distribution in the indium/copper $(\mathrm{In} / \mathrm{Cu})$ specimen during one thermal cycle. The basic parameters and properties of $\mathrm{In}$ and $\mathrm{Cu}$ are shown in Table 1.

Table 1 Material properties and parameters used in simulations of $\mathrm{In} / \mathrm{Cu}$

Indium

\begin{tabular}{|c|c|c|c|}
\hline Length/ mm & 10 & \multirow{2}{*}{$\mathrm{CTE} / \mu \mathrm{m} / \mathrm{m} \mathrm{K}$} & 33 at $300 \mathrm{~K}$ \\
\hline Width/ mm & 0.3 & & 30 at $77 \mathrm{~K}$ \\
\hline Thickness/ mm & 1 & \multirow{2}{*}{$\begin{array}{l}\text { Plastic Properties/ } \\
10^{6}\end{array}$} & \multirow{2}{*}{$\begin{array}{l}2.8-15.0 \quad \text { with } \\
\text { strain variation }\end{array}$} \\
\hline $\begin{array}{l}\text { Young's modulus } \\
\text { /GPa }\end{array}$ & 12.7 & & \\
\hline Poisson's ratio & 0.4498 & Element type & C3D8R \\
\hline \multicolumn{4}{|l|}{ Copper } \\
\hline Length/ mm & 10 & \multirow{2}{*}{$\mathrm{CTE} / \mu \mathrm{m} / \mathrm{m} \mathrm{K}$} & 16.4 at $300 \mathrm{~K}$ \\
\hline Width/ mm & 30 & & $\begin{array}{lll} & 8.21 & \text { at } 77 \\
\mathrm{~K} & & \end{array}$ \\
\hline $\begin{array}{l}\text { Thickness/ } \\
\mathrm{mm}\end{array}$ & 1 & \multirow{2}{*}{$\begin{array}{l}\text { Plastic Properties/ } \\
10^{6}\end{array}$} & \multirow{2}{*}{$\begin{array}{l}68.95-344.8 \\
\text { with strain } \\
\text { variation }\end{array}$} \\
\hline $\begin{array}{l}\text { Young's modulus } \\
\text { /GPa }\end{array}$ & 110 & & \\
\hline Poisson's ratio & 0.343 & Element type & C3D8R \\
\hline
\end{tabular}

The modeling results shown in Figure 9 offer a general insight into the character of stress distribution in indium micro-joint when the temperature returned back to the room temperature from liquid nitrogen. Accordingly, the interface between $\mathrm{In}$ and $\mathrm{Cu}$ is the main location of concerns in terms of the stress concentration, as shown in Figure 10, which shows the match with the results on the possible failure modes for the micro-joint of indium due to thermal cycling. It is worth mentioning that this model was built based on the consideration of hardening with isotropic properties. Since the material properties of indium are anisotropic, rate-dependent and temperature-dependent, not all these parameters required for modeling were available. So the results obtained can provide only a guidance. To best reflect the material behavior, a set of material properties for indium are necessary, and the experimental work is currently carried out to derive such data for future modeling. 


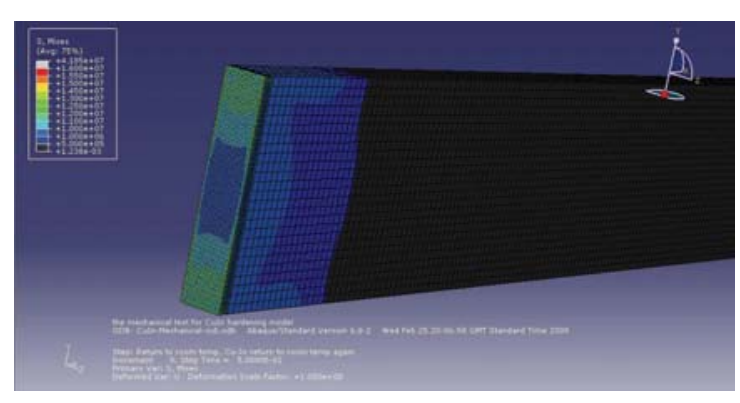

Figure 9 Distribution of Von Mises stress in $\mathrm{In} / \mathrm{Cu}$ in the second half of thermal cycle

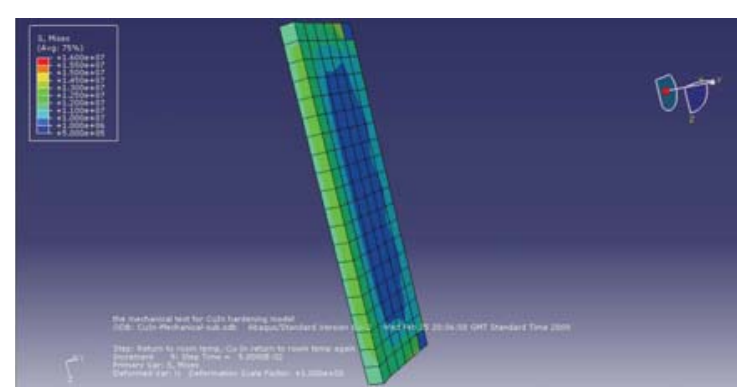

Figure $10 \mathrm{Zoom}$ in of $\mathrm{In} / \mathrm{Cu}$ interface in Figure 9

\section{Conclusions}

The Young's modulus of indium micro-joints after thermal cycling was obtained from the tensile test, which showed a decline from $0.04 \mathrm{MPa}$ to $0.021 \mathrm{MPa}$ with the increase in the number of thermal cycles.

The indium joints at micro scale maintain a good ductility even after 20 thermal cycles, indicating that the failure of such joints is not associated with embitterment of indium.

The finite-element simulations illustrate that the interface between indium and copper can be the potential weak site, which could result in the failure of indium joint as due to high stress concentration.

\section{References}

[1] M. Pötner, B. Donat, A. Benke, Cryogenics, 1991, 31: pp.159-162.

[2] M. Turqueti, S. Cihangir, S. Kwan, IEEE Transactions on Nuclear Science, 2004, 51 (50): pp.2161-2167.

[3] R. P. Reed, C. N. Mcowan, R. E Walsh, Materials Science and Engineering, 1988, A102: pp.227-236.

[4] G. Remaut, A. Lagasse, S. Amelinck, Physics Status Solidi, 1964, 6: pp.723-731

[5] J. H. Becker, B. Chalwers, E. G. Garrow, Acta Crystallogr., 1952, 5: pp.853.

[6] E. O.Hall, Twinning and Diffusionless Transformations in Metals, Butterworth, London, 1954: pp.85-86, 139-144.

[7] M. Wuttig, C. H. Lin, Acta Metall., 1983, 31: pp.11171122.

[8] S. Kim, H. M. Ledbetter, National Institute of Standards and Technology, Boulder, Colorado, Unpublished NIST data, 1987.

[9] C. A. Swenson, Physical Review, 1955, 100(6): pp.16071614. 